\title{
O direito na pós-modernidade
}

\section{Eduardo Carlos Bianca Bittar*}

Sumário: 1. O debate pós-moderno; 2. Modernidade: ordem e progresso?; 3. Os reflexos da pós-modernidade no campo do direito; Conclusões. Referências.

\begin{abstract}
Resumo: A reflexão investiga a noção de pósmodernidade e situa os seus reflexos no campo do direito, tema este que não somente representa um foco importante de pesquisa no estado contemporâneo do debate jurídico, como se torna chave reflexiva de fundamental destaque para operar com as mudanças paradigmáticas no interior do sistema jurídico.
\end{abstract}

Palavras-chave: Modernidade; Pós-modernidade; Crise; Transição paradigmática.

\begin{abstract}
It intends to be an analysis of the post-modernity and its consequences to the law system right can not be understood with an analysis of the changing society of this time, and the investigation intends to understand this questions through the philosophical way.
\end{abstract}

Keywords: Modernity; Post-modernity; crisis; transition.

\section{A pós-modernidade: conceituação e definição}

A expressão 'pós-modernidade' batiza um contexto sócio-histórico particular, que se funda na base de reflexões críticas acerca do esgotamento dos paradigmas instituídos e construídos pela modernidade ocidental. A expressão é polêmica e não gera unanimidades, assim como seu uso não somente é contestado como também se associa a diversas reações ou a concepções divergentes. A literatura a respeito do tema é pródiga, mas as interpretações do fenômeno são as mais divergentes. Ademais, outras expressões já foram indicadas para designar este status quo, com suas diversas projeções sobre a vida humana, dentre elas 'supermodernidade'

\footnotetext{
* Livre-docente e Doutor. Professor Associado do Departamento de Filosofia e Teoria Geral do Direito da Faculdade de Direito da Universidade de São Paulo, nos cursos de graduação e pósgraduação. Professor e pesquisador do Programa de Mestrado em Direitos Humanos do UniFIEO. Presidente da Associação Nacional de Direitos Humanos (ANDHEP) e Pesquisador-sênior do Núcleo de Estudos da Violência (NEV-USP).
} 
(Georges Balandier) e 'modernidade reflexiva' (Ulrich Beck), sem lograr o mesmo êxito ou o mesmo emprego expandido na literatura especializada'.

Apesar de toda a problemática que envolve a afirmação desta expressão, ela parece ter ganhado maior alento no vocabulário filosófico e sociológico (Lyotard, Habermas, Beck, Bauman, Boaventura de Souza Santos) contemporâneo, e ter entrado definitivamente para a linguagem corrente. O curioso é perceber que é esta já a primeira característica da pós-modernidade: a incapacidade de gerar consen$\operatorname{sos}^{2}$.

Mesmo entre os que aceitam o uso do termo para designar um estado atual de coisas, um processo de modificações que se projeta sobre as diversas dimensões da experiência contemporânea de mundo (valores, hábitos, ações grupais, necessidades coletivas, concepções, regras sociais, modos de organização institucional...), não há sequer unanimidade na determinação da data-marco para o início deste processo.

Muito menos que prender-se a datas e referências estanques - e aceitando mesmo os riscos inerentes ao uso e emprego da expressão "pós-modernidade" entende-se interessante a identificação deste processo de ruptura como modo de se diferenciar e de se designar com clareza o período de transição irrompido no final do século XX e que possui por traço principal a superação dos paradigmas erigidos ao longo da modernidade.

A sensação de crise, em amplas magnitudes e alcançando diversos aspectos da vida no século XX, estava sensivelmente presente nos anos 1960, momento em que diversos movimentos globais de protesto e revolta, caracteristicamente

\footnotetext{
${ }^{1}$ Para muitos, acima da própria literatura na área, a afirmação da pós-modernidade ter-se-ia dado com o marco político-referencial da figura de Margaret Thatcher e de seu modelo político: "Margaret Thatcher deve ter compreendido esse estado das coisas de modo intuitivo ao inventar o slogan que afirma que 'não existe de modo algum' algo como a sociedade. Ela é o fenômeno propriamente 'pósmoderno"” (HABERMAS, A constelação pós-nacional: ensaios políticos, Littera-Mundi, 2001, p. 76). Para Bauman: "Não é em toda parte, porém, que essas condições parecem, hoje, estar prevalecendo: é numa época que Anthony Giddens chama de 'modernidade tardia', Ulrich Beck de 'modernidade reflexiva', Georges Balandier de 'supermodernidade', e que eu tenho preferido (junto com muitos outros) chamar de 'pós-moderna': o tempo em que vivemos agora, na nossa parte do mundo (ou, antes, viver nessa época delimita o que vemos como a 'nossa parte do mundo)" (BAUMAN. O malestar da pós-modernidade. Rio de Janeiro: Zahar, 1998, p. 30).

${ }^{2}$ Nisto está o que há de mais próprio na expressão, conforme indica Boaventura de Souza Santos: "Como todas as transições são simultaneamente semi-invisíveis e semicegas, é impossível nomear com exactidão a situação actual. Talvez seja por isso que a designação inadequada de 'pós-moderno' se tornou tão popular. Mas, por essa mesma razão, este termo é autêntico na sua inadequação" (SANTOS, A crítica da razão indolente: contra o desperdício da experiência. São Paulo: Cortez, 2001, p. 50).
} 
antimodernistas, eclodiam no sentido de identificar novas formas de combater a racionalidade brutalizante da vida sob os paradigmas modernos. Se Habermas aponta os anos 1950 e 1960 como favoráveis ao surgimento da pós-modernidade, a culminância de grande significação desta inteira efervescência cultural, social e política ocorre em 1968, em todas as partes do mundo, com as marcantes manifestações estudantis, preparando-se o terreno para o advento de novas identidades ${ }^{3}$.

O esfacelamento da modernidade e a percepção desta sensação de passagem tornam os olhos filosóficos da contemporaneidade críticos de todo o imperialismo da racionalidade moderna. Questionar a modernidade significa pensar o que é a modernidade ou, ainda, ao que ela serviu e o que trouxe de resultados para a vida social desde sua concepção. No lodaçal do em que a filosofia do pós-guerra se encontrava, a consciência dos destinos da modernidade ainda era muito parcamente entrevista. Aliás, aí está já a raiz de toda a dificuldade: se o termo "modernidade" (modernismo) é, em si, um termo ambíguo, o que dizer do termo "pós-modernidade" (pós-modernismo), que carrega em sua estrutura semântica dupla carga de ambigüidades? ${ }^{4}$

A pós-modernidade chega para se instalar definitivamente, mas a modernidade ainda não deixou de estar presente entre nós, e isto é fato. Suas verdades, seus preceitos, seus princípios, suas instituições, seus valores (impregnados do ideário burguês, capitalista e liberal) $)^{5}$, ainda permeiam grande parte das práticas institucionais

\footnotetext{
3 "Embora fracassado, ao menos a partir dos seus próprios termos, o movimento de 1968 tem de ser considerado, no entanto, o arauto cultural e político da subseqüente virada para o pós-modernismo. Em algum ponto entre 1968 e 1972, portanto, vemos o pós-modernismo emergir como um movimento maduro, embora ainda incoerente, a partir da crisálida do movimento antimoderno dos anos 60" (HARVEY. A condição pós-moderna. São Paulo: Loyola, 1992, p. 44).

${ }^{4}$ Quem assinala esta peculiaridade do termo pós-modernismo é Harvey: "Quanto ao sentido do termo, talvez só haja concordância em afirmar que o 'pós-modernismo' representa alguma espécie de reação ao 'modernismo' ou de afastamento dele. Como o sentido de modernismo também é muito confuso, a reação ou afastamento conhecido como 'pós-modernismo' o é duplamente" (HARVEY. A condição pós-moderna. São Paulo: Loyola, 1992, p. 19).

${ }^{5}$ É esclarecedora a lição de Boaventura sobre o paralelismo entre capitalismo e modernidade: "A modernidade ocidental e o capitalismo são dois processos históricos diferentes e autónomos. O paradigma sócio-cultural da modernidade surgiu entre o século XVI e os finais do século XVIII, antes de o capitalismo industrial se ter tornado dominante nos actuais países centrais. A partir daí, os dois processos convergiram e entrecruzaram-se, mas, apesar disso, as condições e a dinâmica do desenvolvimento de cada um mantiveram-se separadas e relativamente autónomas. A modernidade não pressupunha o capitalismo como modo de produção próprio. Na verdade, concebido enquanto modo de produção, o socialismo marxista é também, tal como o capitalismo, parte constitutiva da modernidade. Por outro lado, o capitalismo, longe de pressupor as premissas sócio-culturais da modernidade para se desenvolver, coexistiu e até progrediu em condições consideradas pré-modernas ou mesmo antimodernas" (SANTOS. A crítica da razão indolente: contra o desperdício da experiência. São Paulo: Cortez, 2001, p. 49).
} 
e sociais, de modo que a simples superação imediata da modernidade é ilusão. Obviamente, nenhum processo histórico instaura uma nova ordem, ou uma nova fonte de inspiração de valores sociais, do dia para a noite, e o viver transitivo é exatamente um viver intertemporal, ou seja, entre dois tempos, entre dois universos de valores - enfim, entre passado erodido e presente multifário.

A pós-modernidade, não sendo apenas um movimento intelectual ou, muito menos, um conjunto de idéias críticas quanto à modernidade, vem sendo esculpida na realidade a partir da própria mudança dos valores, dos costumes, dos hábitos sociais, das instituições, sendo que algumas conquistas e desestruturações sociais atestam o estado em que se vive em meio a uma transição. No entanto, a pósmodernidade foi efetivamente constatada, identificada e descrita, assim como batizada e nomeada, a partir de uma tomada de consciência das mudanças que vinham acontecendo e dos rumos tomados pela cultura, pela filosofia e pela sociologia contemporâneas (A filosofia e o espelho da natureza, de Richard Rorty; A condição pós-moderna, de Jean-François Lyotard, com datação de 1979) ${ }^{6}$, dando-se preeminente destaque para a repercussão do texto de Lyotard.

Mas a instauração de uma nova ordem, que irrompe trazendo novas concepções e novos modos de ser, não se faz sem quebras abruptas e sem resistências. Por se tratar de um movimento que está em franco processo de produção, desenrolando-se sob os olhos dos próprios narradores envolvidos, a linha histórica da pósmodernidade ainda é muito tenuemente percebida e muito sutilmente afeita a fortes descrições teóricas. Aliás, mais mitos e lendas, mais fantasias e ilusões estão presentes do que propriamente reais condições empíricas que comprovem esta ou aquela qualidade da pós-modernidade, ou mesmo qual o rumo a ser tomado pelas sociedades a partir das modificações introduzidas ao longo destas últimas décadas.

Em poucas palavras, quer-se dizer que se sabe menos sobre a pós-modernidade do que efetivamente acerca dela se especula. O enevoado diáfano domina o cenário a ponto de tornar-se turva a visão para contemplar o horizonte. Há um grande afã cabalístico, ou até mesmo apocalíptico, nas tentativas de antevisão das conseqüências e dos possíveis frutos advindos da introdução de novos padrões de conduta social com a pós-modernidade. Neste contexto poucas certezas são certas, a não ser aquela que afirma que o certo é não haver certezas?

\footnotetext{
${ }^{6}$ Cf. LEMERT. Pós-modernismo não é o que você pensa. São Paulo: Loyola, 2000, p. 126.

7 "Quem odeia bestas, sapos, aberrações pós-modernas e outras coisas sombrias do tipo pode em algum momento ter exagerado, mas não está errado em se preocupar como se preocupou. $\mathrm{O}$ mundo moderno está passando por alguma espécie de mudança. Mesmo os que desejariam o contrário admitem isso" (LEMERT. Pós-modernismo não é o que você pensa. São Paulo: Loyola, 2000, p. 37).
} 
Como se vem afirmando, a pós-modernidade não surge como algo pensado, não é fruto de uma corrente filosófica. Muito menos constitui um grupo unitário e homogêneo de valores ou modificações facilmente identificáveis, mas configura como que uma força subterrânea a irromper na superfície somente para mostrar seu vigor, aqui e ali, trazendo instabilidade, erosões e erupções, sentidas como abalos da segurança territorial na qual se encontravam anteriormente instaladas as estruturas valorativas e as vigas conceptuais da modernidade. Certa sensação de instabilidade, de incerteza, de indeterminismo paira no ar, simultaneamente a fluxos e ondas de determinismo, de estabilidade conservadora, de certezas e de verdades modernas.

As revoluções que se processam afetam sobretudo a dimensão do cultural ${ }^{8}$. Ora, esta afetação do cultural, por óbvio, gera um choque de culturas entre o novo e o velho, que, até que se estabilizem as crenças e se estabelecem consensos de homogeneidade, gera expectativas, como sói ocorrer sempre no plano cultural. É assim que se pensa estar diretamente relacionada a temática enfocada como tema central destas reflexões, tendo em vista que todo cerne das questões jurídicas está implantado no cerne das questões culturais. Qualquer afetação dos modos pelos quais a cultura é feita traduz-se, quase que imediatamente, em soluções ou crises, em modificações ou alterações, em inovações ou em retrocessos, que afetam diretamente o mundus iuris.

Se o Direito pressupõe certa estabilização de valores majoritários ou consensuais para que a norma exerça seu poder de escolha de conteúdos normativos, a pergunta, num momento transitivo, acaba sendo: quais os consensos possíveis num mundo em transformação? Então passam a ser debates correntes: clonar pessoas ou proibir cientistas de realizar experiências genéticas com seres humanos?; autorizar casamentos entre homossexuais ou proibir a constituição destas sociedades maritais?; diminuir a idade penal e reconhecer a incapacidade da sociedade de atrair novas gerações à consciência social ou deixar relativamente impunes atrocidades cometidas por menores? Diferentemente de como se concebia o Direito como centro de especulações na ideologia burguesa e iluminista dos séculos XVIII e XIX, passa-se a concebê-lo, em meio a tantas transformações sócio-culturais, como um

\footnotetext{
${ }^{8}$ Para checar a revolução operada pelo pós-modernismo é necessário observar suas intromissões no mundo da cultura. É o que afirma Lemert: "Mal se precisa dizer que o pós-modernismo tem algo a ver com o que alegadamente acontece com o modernismo. Assim, se o modernismo é a cultura da Idade Moderna (ou simplesmente da modernidade), pós-modernismo se relaciona com o colapso do modernismo. Logo, se se quer encontrar o pós-modernismo, é necessário antes de tudo olhar a cultura - não porque a cultura seja a única coisa importante do mundo, mas porque é um aspecto particularmente sensível da vida social" (LEMERT. Pós-modernismo não é o que você pensa. São Paulo: Loyola, 2000, p. 43).
} 
processo em transformação, permeável às novas demandas e adaptado aos novos atores sociais.

É certo que tantas turbulências conceituais e valorativas não haveriam de produzir, como conseqüência, senão a criação de um cenário marcante de embates ideológicos acerca das próprias características centrais da pós-modernidade. Todo processo cultural é sempre um processo de reavaliação e de revaloração: a história das culturas é a tradução disto. No entanto, quando a intensificação das modificações reclama uma lavagem simultânea, intensa e profunda de todas as dimensões pelas quais se espraiam as atividades sociais (pense-se nas transformações dos hábitos de consumo, dos modelos de comportamento, das atitudes sexuais, dos sentidos da moda, da vertiginosa aceleração das relações de comunicação, das transformações institucionais, na requalificação das concepções de trabalho etc.), estáse mais do que diante de um simples processo de confronto de gerações com valores diferentes - está-se diante da mudança de uma época, de uma transição intertemporal, fator de polêmicas, rejeições, ansiedades e clamor social. Por isso o que há de curioso nesta expressão é a grande capacidade que possui de gerar dissensos e questionamentos. Há, assim, duas grandes facções: 1. a dos que enfrentam a pós-modernidade com otimismo; 2. a dos que identificam na pósmodernidade motivos suficientes para a xenofobia e a aversão.

A capacidade para gerar atração ou alergia, a capacidade para causar deslumbre ou medo, a capacidade para originar excitação ou insegurança é um atributo específico do novo. A experiência nova, por não vivida e incalculada, traz o gérmen da intranqüilidade pela conseqüência. Restam, então, as perguntas: onde tudo isto vai nos levar?; o que isto haverá de causar?; o que é bom e o que é mau no meio de todas estas mudanças?; onde está o porto seguro?; por que as coisas devem mudar se estavam boas no modo como se conduziam? Projetada sobre a idéia de pósmodernidade está toda uma carga de ansiedade inerente ao processo de vivência do novo (de um novo contraditório, onde valores novos se apresentam como contravalores, que sobrevivem em ondas de contestação ao lado de valores velhos), que descortina dimensões tentadoras e saborosas para os que possuem paladar pelo desconhecido, mas que causam, com a mesma intensidade, o desgosto daqueles que têm paladar pelo trivial.

Portanto, após ter ouvido tantas concepções e destacado a protoformação do conceito de pós-modernidade, ante tantas tentativas, recidivas, idas-e-vindas em torno da expressão, assume-se os riscos de tê-la próxima como modus designandi de um tempo, de um momento, de uma sensação coletiva, que passa a ganhar corpo nas últimas décadas e pode receber o nome de pós-modernidade, com todas as mazelas implicadas na expressão. Se há imprecisões e há contestações, em meio a este tiroteio é que parece interessante assinalar-se o que se entende e o que se assume como pós-modernidade. 
A pós-modernidade, na acepção que se entende cabível, é o estado reflexivo da sociedade ante suas próprias mazelas, capaz de gerar um revisionismo de seu modus actuandi, especialmente considerada a condição de superação do modelo moderno de organização da vida e da sociedade. Nem só de superação se entende viver a pós-modernidade, pois o revisionismo crítico implica praticar a escavação dos erros do passado para a preparação de novas condições de vida.

A pós-modernidade é menos um estado de coisas, exatamente porque ela é uma condição processante de um amadurecimento social, político, econômico e cultural, que haverá de alargar-se por muitas décadas até sua consolidação. Ela não encerra a modernidade, pois inaugura sua mescla com os restos da modernidade. Do modo como se pode compreendê-la, deixa de ser vista somente como um conjunto de condições ambientais para ser vista como certa percepção que parte das consciências acerca da ausência de limites e de segurança, num contexto de transformações, capaz de gerar uma procura (ainda não exaurida) acerca de outros referenciais possíveis para a estruturação da vida (cognitiva, psicológica, afetiva, relacional etc.) e do projeto social (justiça, economia, burocracia, emprego, produção, trabalho etc. $)^{9}$.

\section{Modernidade: ordem e progresso?}

A pós-modernidade vem sendo construída sobre os escombros da modernidade. Sabendo-se que os medievais acreditavam em Deus, sacralizavam rituais de vida em nome de Deus e cometiam barbaridades em nome de Deus, os modernos descobriram um novo Deus, a quem se devota igualmente a mesma dedicação febril e cega: o progresso ${ }^{10}$. Totemizado, este novo Deus da era das luzes polariza as ener-

\footnotetext{
${ }^{9}$ A sensação de insegurança e a percepção das diversas formas de esmagamento dos controles do indivíduo sobre si mesmo já eram percebidos nas décadas de 50 e 60 pela Escola de Frankfurt, como se percebe por esta análise de Horkheimer: "Nessa época de grandes negócios, o empresário independente não é mais uma figura típica. O homem comum acha cada vez mais difícil planejar para os seus herdeiros e mesmo para o seu futuro remoto. O indivíduo contemporâneo pode ter mais oportunidades do que seus ancestrais, mas suas perspectivas concretas têm prazo cada vez mais curto. $\mathrm{O}$ futuro não entra rigorosamente em suas transações. Ele sente apenas que não estará perdido inteiramente se conservar a sua eficiência e a ligação com sua corporação, associação etc. Assim, o sujeito da razão individual tende a tornar-se um ego, encolhido, cativo do presente evanescente, esquecendo o uso das funções intelectuais pelas quais outrora era capaz de transcender a sua real posição na realidade" (HORKHEIMER. Eclipse da razão. São Paulo: Centauro, 2003, p. 142).

10 “A terra prometida é uma das tantas imagens teológicas da fé no progresso, que fundam a história da salvação e, por conseguinte, o conceito mesmo de história" (BORGES. Crítica e teorias da crise. Porto Alegre: EDIPUCRS, 1994, p. 136).
} 
gias sociais focando olhares entusiasmados no amor abstrato ao futuro prometido, ao mesmo tempo em que dá alento a processos de desintegração e provoca profundas distorções na vida social ${ }^{11}$. As promessas nascidas com a modernidade se convertem em realizações materiais inegáveis ${ }^{12}$. Mas a ciência, ao mesmo tempo, converteu a natureza em produto, e uma vez tornada produto sob a lupa de investigação do cientista, também se tornou produto na esteira de produção capitalista. Afirma Horkheimer que "la naturaleza es considerada hoy más que nunca como un mero instrumento de los hombres. Es el objeto de una explotación total, que no conoce objetivo alguno puesto por la razón, y, por lo tanto, ningún límite. El imperialismo limitado del hombre jamás se ve saciado $[\ldots]^{\prime \prime 13}$.

O pragmatismo insaciável, que de tudo retira a aura, nascido desse processo, que se infla da idéia progressista, é o mesmo que alimenta os processos de acelerada destruição do mundo natural e exaustão do ambiente físico sobre o qual se lastreia a própria sobrevivência da humanidade. Em nome do progresso conseguiu-se um regresso tão ilimitado que ameaça colocar a humanidade toda sob uma catastrófica e irreversível barbarização. Mas esta advertência já havia sido feita por Adorno e Horkheimer, quando afirmam: “A maldição do progresso irrefreável é a irrefreável regressão"14. Com isso, o auge da civilização é sua própria aniquilação, e dessa forma se realiza a dialética do esclarecimento.

Mais que isto, o processo de afirmação das sucessivas etapas do capital, do industrial ao financeiro, do nacional ao global, condicionou a identidade humana a um processo de alienação de sua própria natureza, onde o instrumento se converte em fim e os meios operam independentemente do ingrediente humano. Com a modernidade abriu-se campo para a possibilidade de instrumentalização da razão, que agora se converte na inoperância de uma razão que tolera o convívio com a degradação humana, com a violência e com a fome.

No fundo, se trata de perceber que as promessas da modernidade haveriam, paradoxalmente, de conduzir a Auschwitz, que pode ser considerado o trauma do

11 “O progresso, que já foi a manifestação mais extrema do otimismo radical e uma promessa de felicidade universalmente compartilhada e permanente, se afastou totalmente em direção ao pólo oposto, distópico e fatalista da antecipação: ele agora representa a ameaça de uma mudança inexorável e inescapável que, em vez de augurar a paz e o sossego, pressagia somente a crise e a tensão e impede que haja um momento de descanso" (BAUMAN. Tempos líquidos. São Paulo: Zahar, 2007, p. 16). 12 "Não podemos negar o progresso técnico e material; ninguém quer hoje voltar à candeia de azeite e à escravidão - em que pesem os problemas com o meio ambiente e com a formalização do direito - mas são inevitáveis a consideração da idéia mesma de progresso e a sensação de que nessa área do conhecimento e da argumentação não demos ainda um bom passo adiante" (BORGES. Crítica e teorias da crise. São Paulo: Zahar, 1994, p. 228).

${ }^{13}$ HORKHEIMER. Crítica de la razón instrumental. Madrid: Trotta, 2006, p. 127.

${ }^{14}$ ADORNO; HORKHEIMER. Dialética do esclarecimento. Rio de Janeiro: Zahar, 1985, p. 46. 
século XX, quando os ideais da Aufklärung ${ }^{15}$ do século XVIII foram transformados em aparato para a realização de Tánatos ${ }^{16}$. O pensamento de Freud não deixa de ser sensível a esta profunda contradição, o paradoxo da civilização moderna ocidental ${ }^{17}$. Este movimento próprio da dialética da modernidade, que ainda não cessou de operar e que se desdobra com as mais recentes transformações do capitalismo toyotista mundializado, continua a produzir seus efeitos. Desta forma é que nosso tempo se torna uma sucessiva onda de manifestações de violência, atentados, genocídios, guerras e formas de dominação, que tornam a assinatura deste tempo muito mais afim com a dimensão de Tánatos do que com a de Eros ${ }^{18}$. Quando Tánatos ecoa em nosso tempo, a condição hodierna se vê marcada pela indelével marca da ressonância do medo, do temor, da violência, do trauma psicossocial, de cujas ondulações não se podem libertar os indivíduos do hoje ${ }^{19}$. Suas ressonâncias tornam inaudíveis as vozes que falam a favor de Eros.

Trata-se, portanto, de desmistificar a idéia moderna de progresso. À idéia de progresso estão ligados falsos predicados daquilo que o capitalismo por si só não é capaz de fazer. A idéia de progresso está associada à imagem de um "andar para a

\footnotetext{
15 "Seu conteúdo reduzia-se na verdade a isto: todo Aufklärung, até agora, não o era autenticamente e impedia, ao contrário, a realização do verdadeiro Aufklärung" (WIGGERSHAUS. A Escola de Frankfurt: história, desenvolvimento teórico, significação política. Rio de Janeiro: Difel, 2002, p. 364).

16 "Um dos poucos aforismos indubitáveis da Psicanálise é que o nascimento de qualquer forma psíquica é traumático. Qual o trauma fundamental de nosso tempo; digamos, da segunda metade do Século XX?" (HERRMANN, Psicanálise e política: no mundo em que vivemos. In: Percurso. Revista de Psicanálise. São Paulo: Instituto Sedes Sapientiae, ano XVIII, n. 6, 1, 2006, p. 19).

17 “As provas aduzidas por Freud têm duplo aspecto: primeiro, deriva-as analiticamente da teoria dos instintos; e, segundo, encontra analise teórica corroborada pelas grandes doenças e descontentamentos da civilização contemporânea: um ciclo ampliado de guerras, perseguições ubíquas, anti-semitismo, genocídio, intolerância e a imposição de ilusões, trabalho forçado, doença e miséria, no meio de uma riqueza e conhecimento crescentes" (MARCUSE. Eros e civilização: uma interpretação filosófica do pensamento de Freud. Rio de Janeiro: LTC, 1999, p. 83).

18 "Contudo, voltando ao político, a violência desmedida dos próprios atentados terroristas, incluída a imolação do agente, é, em escala, uma reprodução bastante convincente do Grande Atentado que continua suspenso sobre nossas cabeças e ativo na psique social, assim como o são as medidas profiláticas e retaliatórias das potências militares. Digamos que se trata de suicídios coletivizados. Em conjunto, e só em conjunto são compreensíveis, metaforizam pequenas guerras finais, uma atrás da outra" (HERRMANN, Psicanálise e política: no mundo em que vivemos. In: Percurso. Revista de Psicanálise. São Paulo: Instituto Sedes Sapientiae, ano XVIII, n. 6, 1, 2006, p. 21).

19 "Clausewitz afirmou, não sem algum cinismo, que a guerra é a continuação da política por outros meios, e seu dito tornou-se lugar comum. A guerra que não houve, no entanto, tirou as coisas de seus lugares comuns. Porque ela está em curso, é a política de nosso tempo. Seria mais rigoroso, pois, concluir que a política tem sido continuação da guerra por outros meios, menos fragorosos, às vezes mais cruéis" (HERRMANN, Psicanálise e política: no mundo em que vivemos. In: Percurso. Revista de Psicanálise. São Paulo: Instituto Sedes Sapientiae, ano XVIII, n. 6, 1, 2006, p. 24).
} 
frente". Na base dessa filosofia da história forjou-se boa parte das instituições e idéias que marcaram a identidade do discurso moderno. Será que esta imagem sobrevive intacta? Geralmente se costuma "medir" tais passos pela quantificação de índices econômicos, mas no geral esses índices estão dissociados de índices de desenvolvimento humano. A falácia contida na crença na idéia de progresso, e que parece funcionar como superestrutura social para a legitimação das ações de afirmação do capital em direção ao futuro, se expressa pelo fato de que "andando para a frente" também se "marcha para trás". Como afirma Benjamim: "Para que falar de progresso a um mundo que afunda na rigidez cadavérica?" ${ }^{20} \mathrm{O}$ progresso pressupõe dialeticamente crise, de modo que nenhuma crise do capitalismo é acidental, mas parte do processo de afirmação do próprio capital. Um mundo tomado por essa lógica, cuja expansão se dá na base do neoliberalismo internacional, é um mundo tomado por uma parelha de forças que torna incontornável e irreversível a marcha em direção a catástrofes cada vez mais cíclicas, profundas e arrasadoras, tanto do ponto de vista produtivo quanto do ponto de vista econômico e do ponto de vista natural.

A razão instrumental, que converteu a natureza em objeto da volúpia do progresso e do incremento do poder (Macht), acessória da planificação capitalista, é a mesma que orienta e dá condições de expansão ao capital global contemporâneo, o qual - fundando ilusões de vida que se esgotam em consumo e posse - faz com que se respire atualmente uma atmosfera na qual se sente em suspensão o cheiro de morte. Nosso mundo tem odor de morte porque foi convertido em praça de convergência das múltiplas forças do capital mundial. A carnificina implícita provocada pela volúpia do ter é tolerada por parecer faltarem-lhe autoria e culpados diretos. E quando não há a quem imputar direta e visualmente a culpa, parece que a responsabilidade se dilui para o sistema. E, quando se olha para o sistema, ele parece automaticamente responder: "É assim que as coisas funcionam. Não há outro modo". Ao menos, essa é a lei de Fukuyama.

Apesar da aparente vitória do capital, a questão problemática do capitalismo não parece se resolver, pois permanece ameaçada sua sobrevivência futura por limitações que se darão a partir da escassez de recursos e de uma radical intervenção natural sobre os processos econômico-mundiais hodiernos. O fim da história, nos muitos sentidos que esta expressão comporta, tem sido evocado com muita constância por diversas correntes teóricas contemporâneas - o que se processa, todavia, não é o fim da história, mas o fim de uma história. O discurso moderno promoveu às alturas a idéia de que haveria a vitória da civilização, mas o que se vive é o começo do fim de uma barbárie, a exploração do homem pelo homem, o que

\footnotetext{
${ }^{20}$ BENJAMIN, Parque central. In: Obras escolhidas III. São Paulo: Brasiliense, 1989, p. 171.
} 
somente poderá se operar por meio da própria barbárie natural. Em Notas marginais sobre teoria e práxis, Adorno faz a seguinte afirmação: “A recaída já se produziu. Esperá-la para o futuro, depois de Auschwitz e Hiroshima, faz parte do pobre consolo de que ainda é possível esperar algo pior" ${ }^{21}$. À espreita se encontra o desafio de conviver com mais uma crise cíclica do capitalismo, agora global, e seus terrificantes efeitos sociais.

A consciência, portanto, de que violência e degradação são termos presentes na vida hodierna com maior constância do que se deseja, representando um óbice à auto-afirmação da legitimidade do Estado Democrático de Direito, deve permitir que a práxis retome o seu sentido, para significar o "lugar-tenente da liberdade", como afirma Adorno $^{22}$. Se não há liberdade fora da história, é na história que ela pode se realizar, motivo que deve animar o espírito de ação coletiva em direção a conquistas e alternativas ao que está posto, e uma delas está na releitura do sentido do termo "progresso". Com Adorno: "Pode-se imaginar um estado no qual a categoria perca seu sentido que, no entanto, não seja este estado de regressão universal que hoje se associa com o progresso" ${ }^{\text {23 }}$. O progresso deve ser lido e medido não mais por critérios materiais e econômicos simplesmente, mas por outros fatores ligados à realização da dignidade humana. Nestes termos, para Adorno, então, o progresso "transformar-se-ia na resistência contra o perdurável perigo da recaída. Progresso é esta resistência em todos os graus, não o entregar-se à degradação mesma" ${ }^{24}$. A negação da degradação fala a linguagem da dignidade humana e da busca de alternativas à vitória da opressão que se expressa por diversas fontes. Mas isto não é possível sem que os indivíduos se sintam na responsabilidade histórica pela mudança do status quo, baseada na insatisfação com o status quo ${ }^{25}$.

O contrário disso é o convívio com uma sociedade desencantada e que vive a angústia do fim das utopias, da exaustão das grandes metanarrativas, a ascensão de um modo de vida menos político e mais estético, menos coletivo e mais individual, mais leve e consumista, mais líquido e inconsistente, mais frenético e desbussolado.

\footnotetext{
${ }^{21}$ ADORNO, Notas marginais sobre teoria e práxis. In: Palavras e sinais: modelos críticos, 2, Petrópolis: Vozes, 1995, p. 214.

${ }^{22}$ Idem, p. 207.

${ }^{23}$ Idem, p. 61.

${ }^{24}$ Idem, p. 61.

25 "Em outras palavras, é uma recusa a continuar aceitando e a se conformar com a cultura da sociedade estabelecida, não só com as condições econômicas, não só com as instituições políticas, mas com todo o sistema de valores que eles sentem estar apodrecido no âmago. Penso que a esse respeito pode-se de fato falar também de uma revolução cultural. Revolução cultural porque é dirigida contra todo o establishment cultural, incluindo a moralidade da sociedade existente" (MARCUSE, $A$ grande recusa hoje. Rio de Janeiro: Vozes, 1999, ps. 63/ 64).
} 
Certamente, como massa de manobra, este modelo parece ser mais condizente. No entanto, como sentimento, o conformismo derrotista serve de alento ao processo de acovardamento que, antes mesmo de viver a tentativa de intervir na história, encontra nela uma história já narrada e pré-determinada. $\mathrm{O}$ mal que acomete a sociedade contemporânea e seus valores é o mal-estar na pós-modernidade ${ }^{26}$.

\section{Os reflexos da pós-modernidade no campo do direito}

A pós-modernidade, entendida como período de revisão das heranças modernas e como momento histórico de transição no qual se ressente o conjunto dos descalabros da modernidade, produz rupturas e introduz novas definições axiológicas, das quais os primeiros benefícios diretos se podem colher para os sistemas jurídicos contemporâneos (a arbitragem, a conciliação, o pluralismo jurídico, entre outras práticas jurídicas $)^{27}$, e causaram em parte o abalo ainda não plenamente solucionado de estruturas tradicionais, nos âmbitos das políticas públicas, da organização do Estado e na eficácia do direito como instrumento de controle social.

De qualquer forma, a primeira percepção do advento da pós-modernidade e de sua projeção no âmbito jurídico é a de crise, em seu sentido original (krisis, gr. $=$ ruptura, quebra $)^{28}$. A noção de crise vem contextualizada, crescentemente, numa vivência maior da própria crise do capitalismo solidamente constituído, alicerçado em fortes concepções presenciais do Estado intervencionista, condições materiais de expansão dos mercados, amplo espaço para a dominação e a hegemonia das novas ideologias pregadas pela mídia e pelos meios de comunicação, descobertas científicas pluralizando os usos da natureza, políticas internacionais fortalecedoras da consciência de mercado e da expansão multinacional, desenvolvimento acelerado dos meios de transporte que encurtaram distância e reduziram custos, amplo progresso tecnológico e mecânico etc., que é um capitalismo

\footnotetext{
${ }^{26}$ A respeito, vide: BAUMAN. O mal-estar na pós-modernidade. Rio de Janeiro: Zahar, 1998.

${ }^{27}$ A respeito, vide: WOLKMER. Pluralismo jurídico: fundamentos de uma nova cultura no direito. 3. ed. São Paulo: Alfa-Ômega, 2001, ps. 183-210.

${ }^{28} \mathrm{O}$ conceito de crise também possui sua história: "O conceito de crise, desenvolvido na tragédia clássica, tem também uma contrapartida no conceito de crise encontrado na idéia de história enquanto salvação. Esta margem de pensamento entrou nas teorias evolucionistas sociais do século XIX através da filosofia da história do século XVIII. Pois Marx desenvolveu, pela primeira vez, um conceito científico-social de crises sistêmicas; é diante destes antecedentes que falamos hoje de crises sociais ou econômicas" (HABERMAS. A crise de legitimação no capitalismo tardio. Rio de Janeiro: Tempo Brasileiro, 1999, p. 12).
} 
do período fordista ${ }^{29}$ e keynesiano ${ }^{30}$ do pós-guerra (1945-1973), hoje em direção a um toyotismo.

O período progressista, de enriquecimento e estabilidade do capitalismo, logo deu sinais de exaustão, provocando as primeiras desordens. Os anos dourados da propaganda, da música, do sonho americano, da imigração para o continente americano, da reconstrução do pós-guerra, da corrida espacial, da conquista da Lua, logo se transformaram em anos de chumbo, com conseqüências sócio-econômicas as mais nefastas. Isto porque juntamente com a crise econômica adveio a crise do próprio Estado, tais os comprometimentos entre as duas instâncias ${ }^{31}$.

Não se trata de uma mera crise econômica por desestabilidade monetária ou especulativa, mas sim de algo estrutural para a sociedade, capaz de afetar as economias mais estáveis do planeta ${ }^{32}$, projetando-se da seguinte para Habermas: tendo como ponto de origem o sistema econômico, uma crise econômica de caráter sistêmico; tendo como ponto de origem o sistema político, uma crise de racionalidade de caráter sistêmico e uma crise de legitimação (identidade); tendo como ponto de origem o sistema sócio-cultural, uma crise de motivação ${ }^{33}$.

Juntamente com estes fatos, os conflitos deixam de ter a proporção e a perspectiva de conflitos individuais e passam a conflitos conjunturais, coletivos, associativos, difusos, transindividuais, motivando o colapso das formas tradicionais

\footnotetext{
29 “A data inicial simbólica do fordismo deve por certo ser 1914, quando Henry Ford introduziu seu dia de 8 horas e 5 dólares como recompensa para os trabalhadores da linha automática de montagem de carros que ele estabelecera no ano anterior em Dearbon, Michigan" (HARVEY. A condição pósmoderna. São Paulo: Loyola, 1992, p. 121).

30 "Os princípios da administração científica, de F. W. Taylor - um influente tratado que descrevia como a produtividade do trabalho podia ser radicalmente aumentada através da decomposição de cada processo de trabalho em movimentos componentes e da organização de tarefas de trabalho fragmentadas segundo, padrões rigorosos de tempo e estudo do movimento -, tinham sido publicados, afinal, em 1911" (HARVEY. A condição pós-moderna. São Paulo: Loyola, 1992, p. 121).

31 "Se as tendências à crise econômica persistem no capitalismo avançado, isto indica que as ações governamentais, intervindo no processo de realização, obedecem não menos que os processos de troca, às leis econômicas operando espontaneamente" (HABERMAS. A crise de legitimação no capitalismo tardio. Rio de Janeiro: Tempo Brasileiro, 1999, p. 63).

32 "Vivemos hoje numa época caracterizada tanto pelo lento declínio do império americano, que nasceu dos escombros dos impérios britânico, francês e holandês, entre outros, como pela súbita queda da vasta ordem imperial da União Soviética. Se há, como se diz, uma nova ordem mundial, tratase na melhor das hipóteses da nervosa ordem da fala sobre, e da denúncia de, múltiplas vozes que, devido a seu silêncio até agora longo, não tinham sido realmente consideradas vozes de outros indivíduos que de fato existem" (LEMERT. Pós-modernismo não é o que você pensa. São Paulo: Loyola, 2000, p. 148).

${ }^{33} \mathrm{Cf}$. HABERMAS. A crise de legitimação no capitalismo tardio. Rio de Janeiro: Tempo Brasileiro, 1999, p. 62.
} 
de se atender a demandas para as quais somente se conheciam mecanismos típicos do Estado liberal, estruturado sobre as categorias do individual e do burguês. Enfraquecido capitalisticamente $(1965 / 1973)^{34}$, o Estado perdia um de seus maiores arcabouços de manutenção da hegemonia social e de monopólio da violência: a legislação ${ }^{35}$. Passa-se a perceber, a partir da década de 1970, um crescimento abrupto das taxas de criminalidade, pobreza, diferenças sociais, crises e movimentos de trabalhadores, mobilizações, greves e guerrilhas civis, formas pelas quais a sociedade reage ao processo de sua complexização perante a cultura pós-moderna em ascensão. A erosão trazida introduz um processo de transição, ao qual, com Boaventura de Souza Santos, está-se chamando de transição paradigmática, o que não se faz sem estremecimentos naturais e sem muitas turbulências, algumas já enfrentadas, outras ainda a enfrentar ${ }^{36}$.

Percebe-se, neste contexto de crise, que o mundo é um projeto inacabado; a história é seu eixo de movimentação e realização. Em contínua construção e reconstrução de seus valores, a humanidade não pode prescindir de longos processos de maturação axiológica. A ingenuidade das idéias que constituem o cerne das propostas da modernidade é ter acreditado que se tratava de respostas definitivas para os problemas humanos e que o modelo da ciência cartesiana era suficiente para explicar e devassar a verdade de todas as coisas. O positivismo, por sua vez, exacerbou o raciocínio segundo o qual a evolução humana ter-se-ia dado pela superação das etapas mítica e metafísica à era positiva, à era da ciência. A ilusão da objetividade havia alcançado o pensamento ocidental.

\footnotetext{
34 "De modo mais geral, o período de 1965 a 1973 tornou cada vez mais evidente a incapacidade do fordismo e do keynesianismo de conter as contradições inerentes ao capitalismo" (HARVEY. A condição pós-moderna. São Paulo: Loyola, 1992, p. 135).

${ }^{35}$ Quando se detecta a crise, Habermas propõe a seguinte observação: 1. Crise econômica: a) o aparelho do Estado age como órgão executivo inconsciente, à maneira natural, da lei do valor; b) o aparelho do Estado age como agente planejador do "capital monopolista" unificado; 2. Crise de racionalidade: ocorre a destruição da racionalidade administrativa através de: c) interesses opostos dos capitalistas individuais; d) produção (necessária para contínua existência) de estruturas alheias ao sistema; 3. Crise de legitimação: e) limites sistemáticos; f) efeitos colaterais não-desejados (politização) das intervenções administrativas na tradição cultural; g) crise de motivação; h) erosão de tradições importantes para a existência contínua do sistema; i) sobrecarga através de sistemas universalistas de valores e "novas" necessidades) (HABERMAS. A crise de legitimação no capitalismo tardio. Rio de Janeiro: Tempo Brasileiro, 1999, p. 67).

${ }^{36}$ Nesta transição, adensam-se os conflitos, multiplicam-se as formas de inconsistência do sistema oficial, idealizado para retratar uma sociedade moldada sob cânones e princípios liberais, burgueses, capitalistas, progressistas e cientificistas: "Uma transição paradigmática é um longo processo caracterizado por uma suspensão 'anormal' das determinações sociais que dá origem a novos perigos, riscos e inseguranças, mas que também aumenta as oportunidades para a inovação, a criatividade e a opção moral” (SANTOS. A crítica da razão indolente: contra o desperdício da experiência. São Paulo: Cortez, 2001, p. 186).
} 
Desta forma se forjaram os principais paradigmas do Estado de Direito e da dogmática jurídica durante o século XIX. Concebeu-se, neste sentido, a experiência de um Estado legalista, que se movimenta a partir de uma imensa miríade de textos normativos, atos burocráticos, expedientes dispendiosos, mas que, vivenciando a crise contemporânea, é incapaz de conter delitos os mais banais ou mesmo dar efetividade a normas de importância social reconhecida. Enquanto as normas e os atos administrativos, as portarias e os expedientes burocráticos se reproduzem, multiplicam e pluralizam, também os crimes, atrocidades, contradições sistêmicas, atos abusivos e a corrupção aumentam sua participação na desconstituição do espaço de respeitabilidade do ordenamento jurídico.

Validade, legalidade, ordem, impositividade, eram considerados valores supremos de um ordenamento que operava como uma razão científica para a disciplinação da ordem e da desordem sociais. O Estado liberal nasce sob estes dísticos e cristaliza toda uma cultura jurídica que haverá de contaminar as mentalidades do século $\mathrm{XX}$, mantendo-se estável até os mais notáveis sinais de crise desmascararem as pretensões de validade universal e objetividade, de igualdade formal e de regramento social sancionado atribuídos ao ordenamento jurídico. O legal e o racional (poder e saber, na leitura foucaultiana) se somam para o combate ao ilegal e ao irracional, que são condenados ao exílio social, à estranheza, ao porão, à prisão ${ }^{37}$.

Neste sentido, contemporaneamente, percebe-se que a legalidade deixa de ser princípio de efetividade do Estado Democrático de Direito e passa a ser medida de contenção ideológica das mazelas formais do sistema jurídico. Trata-se de expediente ideológico porque mantém a estrutura social intacta, ou seja, não intervém de fato na realidade histórica e concreta na qual se encontram os agentes sociais, construindo-se apenas no sentido de sustentar a justificativa do sistema. Neste sentido é que promessas irrealizáveis, normas abusivamente programáticas, conceitos vagos são texto constitucional sem o respectivo conseqüente na realidade social. Há, percebe-se, todo um conjunto de necessidades vivendo e convivendo com uma demanda reprimida por justiça social.

Os tradicionais paradigmas que serviram bem ao Estado de Direito do século XIX não se encaixam mais para formar a peça articulada de que necessita o Estado contemporâneo para a execução de políticas públicas efetivas. Assim, perdem significação: a universalidade da lei, pois os atores sociais possuem características peculiares não divisáveis pela legislação abstrata; o princípio da objetividade do

\footnotetext{
${ }^{37}$ E estes números são expressivos mesmo em sociedade industrializadas e ditas de Primeiro Mundo: "Todo ano, um milhão e meio de americanos povoam as prisões americanas. Cerca de quatro e meio milhões de americanos adultos estão sob alguma forma de controle judicial" (BAUMAN. O malestar da pós-modernidade. Rio de Janeiro: Zahar, 1998, p. 59).
} 
direito, que o torna formalmente isento de qualquer contaminação de forças políticas, quando se sabe que toda a legislação vem formulada na base de negociações políticas e partidárias; a idéia da contenção do arbítrio pela lei, fator em descrédito frente à ineficácia e à inefetividade das atitudes de combate à corrupção e às taxas elevadíssimas de impunidade; a regra de igualdade perante a lei, como garantia da indistinção e do deferimento dos mesmos direitos a sujeitos igualmente capazes e produtivos no mercado, quando se sabe que as oportunidades são maiores para uns e menores para outros; a idéia de que a codificação representaria uma obra científico-legislativa, obra-prima do saber jurídico, com disciplina única e sistemática das matérias por ele versadas, insuscetíveis de lacunas e de erronias, possibilitando a exegese harmônica do sistema, quando se sabe que os códigos possuem o mesmo potencial de dissincronia com as mudanças sociais que os demais textos normativos; a tripartição clara das competências das esferas e das instâncias do poder como forma de manter o equilíbrio do Estado, o que na prática resulta em dissintonia entre as políticas legislativas, as políticas judiciárias e as políticas administrativas e governamentais, criando Estados simultâneos orientados por valores desconexos; a idéia da democracia representativa como fomento à igualdade de todos e à realização da vontade geral rousseauniana, quando se sabe que a população vive à mercê dos usos e abusos na publicidade, no discurso e na manipulação políticas; a intocabilidade da soberania, como forma de garantia da esfera de atuação com exclusividade dos poderes legislativos, jurisdicionais e executivos em bases territoriais fixas e determinadas na ordem internacional, quando se sabe que a interface da internacionalização dos mercados e da interdependência econômica tornam inevitável o processo de integração; a garantia de direitos universais de primeira geração, como forma de expressar a proteção à pessoa humana, o que na prática ainda pouco se incorporou às realizações sócio-econômicas; a garantia da existência da jurisdição como garantia de acesso a direitos, quando se sabe que, em verdade, a justiça se diferencia para ricos e pobres, pelos modos como se pratica e pelas deficiências reais de acesso que possui.

Enquanto se fala em princípio da legalidade, em respeito aos direitos fundamentais etc., detentos são espancados sob a custódia carcerária do Estado, pessoas são violentadas em número crescente nas ruas dos grandes centros urbanos, mulheres são estupradas em ruas ausentes de fiscalização e policiamento, taxas insuportáveis de crianças morrem de fome e, inexplicavelmente, doentes morrem em filas de hospitais... Em lugar das certezas modernas (verdade, ciência, ordem, regra, poder central, norma, código, capital, produção, propriedade, sistema etc.), outro quadro se instaura em seu lugar, com indícios e características da mudança paradigmática, identificáveis a partir de algumas palavras: desmantelamento; desagregação; banalização; abalo; desordem; ilegalidade; contracultura; ineficácia. 
Eis o quadro da pós-modernidade na caracterização do sócio-jurídico, procurando-se acentuar a importância da revitalização de valores perdidos durante a modernidade como modo de aquietação de diversas questões candentes no plano da justiça social. O surreal na caracterização do quadro está propriamente no descompasso, ou na contradição, entre a ordem formal (irreal) e a ordem social (real). Eis o que desafia o direito, bem como a ciência do direito, de um modo geral, a repensar seus próprios conceitos, práticas, valores e paradigmas.

\section{Conclusões}

Cumpre dizer que esta investigação em torno dos reflexos da pós-modernidade no Direito traz como reflexão um mapeamento filosófico, numa linha empírica de questionamento, das principais perplexidades retiradas da vivência quotidiana do fenômeno jurídico. Muito menos voltada para a dissecação formal do objeto de pesquisa, muito menos dedicada à elucidação meramente teórica da problemática, a discussão trazida ao longo das páginas deste trabalho repousa, invariavelmente, sobre as diversas esferas - a social, a cultural, a política e a econômica - vividas contemporaneamente, com ênfase para a realidade brasileira.

A pós-modernidade é identificada conceitualmente, estudada na boca dos teóricos, mas sobretudo vista em sua real condição, ou seja, como fase histórica responsável por modificações e alterações imprevisíveis no contexto das relações humanas e, por conseqüência, no contexto das relações sócio-jurídicas. A pósmodernidade trouxe progressos, trouxe importantes aquisições e talvez represente uma importante fase de superação da humanidade de seus cânones e de seus valores, sobretudo aqueles de inspiração moderna. O que se quis foi recensear como o fenômeno jurídico vem vivenciando este momento de passagem, do moderno ao pós-moderno. Ainda mais, procurou-se estudar o conjunto de elementos determinantes que marcam a contradição da tradição jurídica, em grande parte formada ao longo da modernidade (Revolução Francesa, quebra do absolutismo, ascensão da ciência, declarações de direitos, formação do Estado, ascensão da burguesia, expansão do liberalismo econômico, controle democrático do despotismo político, consolidação do positivismo jurídico, desenvolvimento das tecnologias dogmáticas, consolidação da ciência do direito etc.), com as inovações trazidas pela pós-modernidade à vida social.

Ora, a crise, em seus diversos aspectos (econômico, político, cultural, moral, burocrático etc.), tem sido a geradora de um estado de alta combustão social, pois as sociopatias se multiplicam sem solução material ou formal e inclusive à revelia do Estado, aquele ente moral criado pela cultura moderna como sendo o responsável 
pelo controle dos comportamentos sociais e pela pacificação do convívio social. Os desvios sentidos e vividos ao longo deste processo são, por sua vez, causa de novos conflitos, que se renovam e multiplicam em novas perspectivas, em grau mais acelerado e complexo que a própria velocidade e capacidade do Estado de Direito de administrá-los. Lançando as bases de um debate sobre a qualidade do direito que se quer, em face do direito que se tem, o artigo apresenta a sua utilidade para toda tentativa de recomeçar, no interior da cultura do direito, a partir de novas bases.

\section{Referências}

ADORNO, Theodor W. Notas marginais sobre teoria e práxis. In: Palavra e sinais: modelos críticos, 2. Tradução de Maria Helena Ruschel. Petrópolis: Vozes, 1995.

. Progresso. In: Palavra e sinais: modelos críticos, 2. Tradução de Maria Helena Ruschel. Petrópolis: Vozes, 1995.

; HORKHEIMER, Max. Dialética do esclarecimento: fragmentos filosóficos. Trad. Guido Antonio de Almeida. Rio de Janeiro: Zahar, 1985.

BAUMAN, Zygmunt. Ética pós-moderna. Trad. João Rezende Costa. São Paulo: Paulus, 1997. 2000.

. Em busca da política. Trad. Marcus Penchel. Rio de Janeiro: Zahar,

. O mal-estar da pós-modernidade. Trad. Mauro Gama e Cláudia Martinelli Gama. Rio de Janeiro: Zahar, 1998.

. La globalización: consecuencias humanas. Trad. Daniel Zadunaisky. 2. ed. México: Fondo de Cultura Económica, 2001.

. Modernidade líquida. Trad. Plínio Dentzein. Rio de Janeiro: Zahar, 2001.

Modernidade e ambivalência. Rio de Janeiro: Zahar, 1999.

. Tempos líquidos. Trad. Carlos Alberto Medeiros. São Paulo: Zahar, 2007.

BENJAMIN, Walter, Parque central. In: Obras escolhidas, III. Trad. José Martins Barbosa e Hemerson Alves Baptista. São Paulo: Brasiliense, 1989.

BERCOVICI, Gilberto. Desigualdades regionais, estado e constituição. São Paulo: Max Limonad, 2003.

BITTAR, Eduardo C. B. O direito na pós-modernidade. Rio de Janeiro: Forense Universitária, 2005. 
BORGES, Bento Itamar. Crítica e teorias da crise. Porto Alegre: EDIPUCRS, 2004.

CASTANHEIRA NEVES, A. A crise actual da filosofia do direito no contexto da crise global da filosofia: tópicos para a possibilidade de uma reflexiva reabilitação. Boletim da Faculdade de Direito de Coimbra. Coimbra: Coimbra, 2003.

. O direito hoje e com que sentido? O problema actual da autonomia do direito. Lisboa: Piaget, 2002.

CASTORIADIS, Cornelius. O mundo fragmentado: as encruzilhadas do labirinto. Trad. Ana Barradas. Lisboa: Campo da Comunicação, 2003.

COELHO, Luiz Fernando. A teoria do direito na pós-modernidade. São Paulo, 2002. Disponível em: $<$ http://www2.uerj.br/ direito/publicacoes/maisartigos/a-teoria-critica.html>. Acesso em: 26 ago. 2002.

COMPARATO, Fábio Konder. A construção histórica dos direitos humanos. São Paulo: Saraiva, 1999.

CUNHA, Paulo Ferreira da. O Ponto de Arquimedes: natureza humana, direito natural, direitos humanos. Coimbra: Almedina, 2001.

DUPAS, Gilberto. Ética e poder na sociedade da informação. 2. ed. São Paulo: UNESP, 2001.

FARIA, José Eduardo O. C. O direito na economia globalizada. São Paulo: Malheiros, 1999.

. O futuro dos direitos humanos após a globalização econômica. $O$ cinqüentenário da Declaração Universal dos Direitos do Homem. AMARAL JÚNIOR, Alberto do; PERRONE-MOISÉS, Claudia (orgs.). São Paulo: USP, 1999.

FROMM, Erich. Ter ou ser? Trad. Nathanael C. Caixeiro. 4. ed. São Paulo: LTC, 1987.

GIDDENS, Anthony. As conseqüências da modernidade. Trad. Raul Fiker. São Paulo: UNESP, 1991.

; BECK, Ulrich; LASH, Scott. Modernização reflexiva: política, tradição e estética na ordem social moderna. Trad. Magda Lopes. São Paulo: Universidade Estadual Paulista, 1997.

GUARDINI, Romano. O fim da Idade Moderna: em procura de uma orientação. Lisboa: Edições 70, 2000.

HABERMAS, Jürgen. A crise de legitimação do capitalismo tardio. 3. ed.

Trad. Vamireh Chacon. Rio de Janeiro: Tempo Brasileiro, 1999. 
. O discurso filosófico da modernidade. Trad. Ana Maria Bernardo, José Rui Meirelles Pereira, Manuel José Simões Loureiro, Maria Antónia Espadinha Soares, Maria Helena Rodrigues de Carvalho, Maria Leopoldina de Almeida, Sara Cabral Seruya. Lisboa: Dom Quixote, 1990.

. A inclusão do outro: estudos de teoria política. Trad. George Spencer e Paulo Astor Soethe. São Paulo: Loyola, 2002.

. Bestialidade e humanidade. Cadernos de filosofia alemã. Trad. Luiz Repa. São Paulo: USP, 1999.

. Consciência moral e agir comunicativo. Trad. Guido A. de Almeida. Rio de Janeiro: Tempo Brasileiro, 1989.

. Écrits politiques. Trad. Christian Bouchindhomme e Rainer Rochlitz. Paris: CERF, 1990.

. A constelação pós-nacional: ensaios políticos. Trad. Márcio SeligmanSilva. São Paulo: Littera-Mundi, 2001.

HARVEY, David. Condição pós-moderna: uma pesquisa sobre as origens da mudança cultural. Trad. Adail Ubirajara Sobral e Maria Stela Gonçalves. São Paulo: Loyola, 2002.

HELLER, Agnes; HÉHER, Ferenc. A condição política pós-moderna. Trad. Marcos Santarrita. Rio de Janeiro: Civilização Brasileira, 1998.

HERMANN, Fábio. Psicanálise e política: no mundo em que vivemos. In: Percurso, Revista de Psicanálise, ano XVIII, n. 36, ps. 5-25, 2006.

HOBSBAWN, Eric. Era dos extremos: o breve século XX. 2. ed. Trad. Marcos Santarrita. São Paulo: Companhia das Letras, 1995.

. O novo século. Trad. Allan Cameron e Claudio Marcondes. São Paulo: Companhia das Letras, 2000.

HORKHEIMER, Max. Eclipse da razão. Trad. Sebastião Uchoa Leite. São Paulo: Centauro, 2002.

Trotta, 2002.

. Crítica de la razón instrumental. Trad. Jacobo Muñoz. Madrid:

LEMERT, Charles. Pós-modernismo não é o que você pensa. Trad. Adail Ubirajara Sobral. São Paulo: Loyola, 2000.

LIPOVETSKY, Gilles. L'ère du vide: essais sur l'individualisme contemporain. Paris: Gallimard, 1993.

Barcarolla, 2004.

. Os tempos hipermodernos. Trad. Mário Villela. São Paulo: 
LUHMANN, Niklas. Sociologia do direito. Trad. Gustavo Bayer. Rio de Janeiro: Tempo Brasileiro, 1983.

LYOTARD, Jean-François. A condição pós-moderna. 2. ed. Trad. José Bragança de Miranda. Lisboa: Gradiva, 1989.

MARCUSE, Herbert. A grande recusa hoje. LOUREIRO, Isabel (org.). Trad. Isabel Loureiro e Robespierre de Oliveira. Rio de Janeiro: Vozes, 1999.

. Eros e civilização: uma interpretação filosófica do pensamento de

Freud. Trad. Álvaro Cabral. 8. ed. Rio de Janeiro: LTC, 1999.

SANTOS, Boaventura de Souza. Reconhecer para libertar: os caminhos do cosmopolitismo multicultural. São Paulo: Difel, 2003.

. A crítica da razão indolente: contra o desperdício da experiência. São Paulo: Cortez, 2001.

. Introdução a uma ciência pós-moderna. Rio de Janeiro: Graal, 1989.

SOUTO, Claudio; FALCÃO, Joaquim. Sociologia e direito: textos básicos para a disciplina de sociologia jurídica. São Paulo: Thomson, 1999.

SOUZA JÚNIOR, José Geraldo de. Sociologia jurídica: condições sociais e possibilidades teóricas. Porto Alegre: Fabris, 2002.

WIGGERSHAUS, Rolf. A Escola de Frankfurt: história, desenvolvimento teórico, significação política. Rio de Janeiro: Difel, 2002.

WOLKMER, Antonio Carlos. Pluralismo jurídico: fundamentos de uma nova cultura no direito. 3. ed. São Paulo: Alfa-Ômega, 2001. 